\title{
Colonic Perforations after Gas Explosion Induced by Argon Plasma Coagulation
}

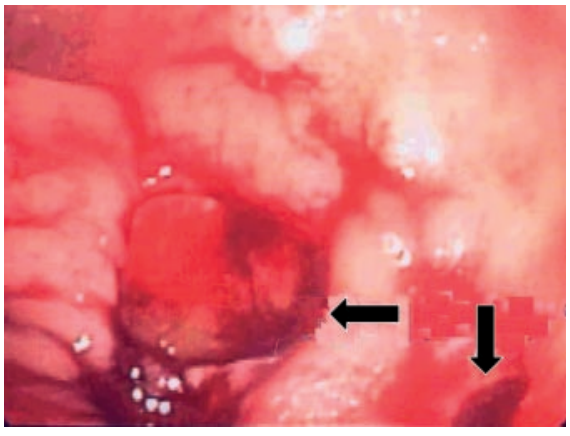

Figure 1 Colonoscopy after the explosion, showing a sigmoid colon completely clean after preparation with water and saline enemas, and two of the three sigmoid-perforating lesions.

Three factors are necessary to trigger an explosion of intestinal gases: the presence of combustible gases (hydrogen, methane), the presence of combustive gas (oxygen), and an initiating heat source (endoscopic or surgical electrocautery) [1].

An 82-year-old woman was admitted for treatment by endoscopic argon plasma coagulation (APC) of a tubulovillous adenoma of the sigmoid colon, with a focus of high-grade dysplasia. Preparation by intestinal enemas with saline water was carried out. Thermal injury using a standard endoscopic APC probe interfaced with an electrosurgical generator (ERBE 300) was induced. The argon gas flow was set at $0.7 \mathrm{l} /$ minute and the electrosurgical generator was set to deliver $50 \mathrm{~W}$. A loud explosion occurred in the colon immediately after the first spark induced by APC and the colonoscope was completely ejected. The colonoscope was inserted again and showed three sigmoid-perforating lesions (Figure 1). A celioscopy was immediately carried out, and showed three full-thickness sigmoid perforations (Figure 2). These were sutured with manual and mechanical suturing under celioscopic guidance.

To prevent the risk of explosive gas mixtures in the large bowel, administration of oral antibiotics before endoscopic pro-

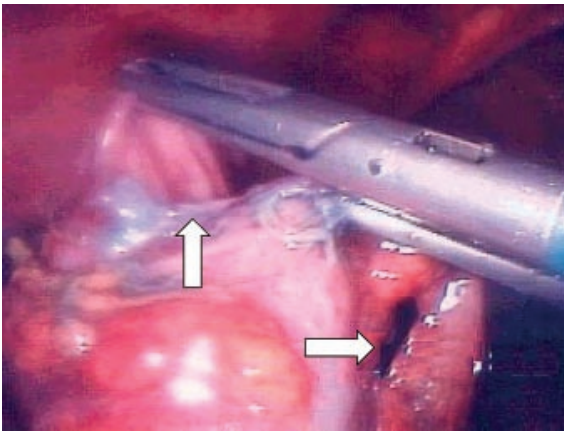

Figure 2 Celioscopy showing two of the three full-thickness lacerations in the sigmoid colon, the absence of hemoperitoneum and no more fecal matter in the abdomen.

cedures and insufflation of inert gas have been suggested, but these approaches are debated. Use of oral mannitol is now avoided in the preparation of the colon, and other methods (use of polyethylene glycol solution, sodium phosphate solution, castor oil, or saline water enemas) are less often implicated in bowel gas explosions [2]. It remains unknown to what extent a standard preparation for sigmoidoscopy makes the bowel safe for APC [3].

At lower energy levels (45 W), APC has been reported to be an effective therapy, with a limited depth of injury increasing the risk of colonic perforation. APC provides the initiating heat source which can trigger the explosion of gases in the colon [4].

The usual treatment of lesions caused by gas explosion in the colon is urgent colectomy by laparotomy [5]. In the absence of signs of peritonitis, a celioscopic treatment was possible with our patient.

\section{N. Pichon ${ }^{1}$, F. Maisonnette ${ }^{2}$, F. Cessot ${ }^{1}$, M. Sodji ${ }^{2}$, D. Sautereau ${ }^{1}$ \\ ${ }^{1}$ Department of Gastroenterology, Dupuytren University Hospital, Limoges, France \\ ${ }^{2}$ Department of Surgery, Dupuytren University Hospital, Limoges, France.}

\section{References}

${ }^{1}$ De Wilt JH, Borel RinkesIH, Brouwer KJ. Gas explosion during colonic surgery. J R Coll Surg (Edinb) 1996; 41: 419

${ }^{2}$ Keighley MR, Taylor EW, Hares MM et al. Potentially explosive colonic concentrations of hydrogen after bowel preparation with mannitol. Lancet 1981; 1: 634-636

${ }^{3}$ Monahan DW, Peluso FE, Goldner F. Combustible colonic gas levels during flexible sigmoidoscopy and colonoscopy. Gastrointest Endosc 1992; 38: 4043

${ }^{4}$ Norton ID, Wang L, Levine SA et al. In vivo characterization of colonic thermal injury caused by plasma argon coagulation. Gastrointest Endosc 2002; 55: 631- 636

${ }^{5}$ Bisson B. Methane gas explosion during colonoscopy. Gastroenterol Nurs 1997; 20: $136-137$

\section{Corresponding Author}

\section{N. Pichon, M.D.}

Gastroenterologie

CHU Dupuytren

2 avenue Martin Luther King

87042 Limoges

France

Fax: +33-5-55056630

E-mail: n.pichon@libertysurf.fr 